\title{
Polychlorinated biphenyls (PCBs) in air and soil from a high-altitude pasture in the Italian Alps: evidence of CB-209 contamination
}

\author{
Paolo Tremolada ${ }^{1} \cdot$ Niccolò Guazzoni $^{1} \cdot$ Roberto Comolli $^{2} \cdot$ Marco Parolini $^{1}$ • \\ Serena Lazzaro ${ }^{1} \cdot$ Andrea Binelli $^{1}$
}

Received: 27 April 2015 / Accepted: 22 July 2015

(C) Springer-Verlag Berlin Heidelberg 2015

\begin{abstract}
This study analyses the seasonal trend of polychlorinated biphenyls (PCB) concentrations in air and soil from a high-altitude mountain pasture in the Italian Alps. PCB concentrations in soil were generally comparable to background levels and were lower than those previously measured in the same area. Only CB-209 unexpectedly showed high concentrations with respect to the other congeners. GC-MSMS identification was very clear, rising a new problem of increasing PCB contamination concerning only CB-209, which is not present in commercial mixtures used in the past in Italy and Europe. Considering all of the congeners, seasonal PCB trends were observed both in air and in soil that were related to the temperature and precipitation measured specifically in the study area. Highly significant relationships were found between the temperature-normalised concentrations in soil and the precipitation amounts. A north/south enrichment factor was present only in soil with rapid early summer revolatilisation kinetics from soil to air and autumn re-
\end{abstract}

Responsible editor: Hongwen Sun

Capsule Quite high concentrations of CB-209 were found in mountain soils; this finding and other evidences from literature highlight the possible 'new' threat coming from this contaminant.

Electronic supplementary material The online version of this article (doi:10.1007/s11356-015-5115-1) contains supplementary material, which is available to authorized users.

Paolo Tremolada

paolo.tremolada@unimi.it

1 Department of Biosciences, University of Milan, Via Celoria 26, 20133 Milan, Italy

2 Department of Environmental and Land Sciences (DISAT), University of Milan Bicocca, Piazza della Scienza 1, 20126 Milan, Italy deposition events from air to soil. Fugacity ratio calculations confirmed these trends. Surface soils respond rapidly to meteorological variables, while subsurface soils respond much more slowly. Seasonal trends were different for the northern and southern sides of the mountain. A detailed picture of the interactions among temperature, precipitation, mountain aspects and soil features was obtained.

Keywords PCBs · CB-209 - Soil contamination · Air contamination $\cdot$ Seasonal trends $\cdot$ Air-soil exchange

\section{Introduction}

Polychlorinated biphenyls (PCBs) require continuous attention because of their ubiquity, persistence and toxicity (Helyar et al. 2009; Johnson et al. 2009; Bettinetti et al. 2012). Mountains are an important sink for persistent organic pollutants (POPs) because of their characteristics. In fact, the high organic matter content of soils, low temperatures and efficient snow scavenging emphasise the retention of semi-volatile organic pollutants (Lei and Wania 2004; Dalla Valle et al. 2005; Vighi 2006). Many studies have been conducted worldwide to assess POP levels and distribution in mountain areas (e.g. Grimalt et al. 2001; Barra et al. 2005; Wang et al. 2006, 2007; Nizzetto et al. 2008; Moeckel et al. 2008; Tremolada et al. 2009a).

Geographical area (proximity to emission sources) and time (proximity to emission peaks) justify the large concentration differences of several orders of magnitude at the global scale (Meijer et al. 2003), but rather high concentration differences have been observed with respect to the same time and area (Tremolada et al. 2010; Guazzoni et al. 2011). This smallscale and short-time local variability can cause a maximum concentration difference of 1 order of magnitude in the soil 
because of the organic matter content of the soil (Meijer et al. 2002, 2003; Sweetman et al. 2005), the soil layer (Pan et al. 2006; Tremolada et al. 2012), the aspect (Tremolada et al. 2009a) and the time during the snow-free season (from May until November). An annual cycle of pollutant emission and deposition is present in soil (Tremolada et al. 2009b). During the winter season, low temperatures and snowy precipitation cause an efficient deposition of airborne pollutants and their retention in the snow mantle (Lei and Wania 2004; Wania et al. 1998a). During spring, the snow mantle melts and releases pollutants back to the atmosphere or to the soil by the melting water-soil interaction (Meyer et al. 2006; Meyer and Wania 2008). During thaw, the soil surface is available to receive contaminants because of its low temperature (near $0^{\circ} \mathrm{C}$ ). Later, soil temperatures start to increase, reaching quite high temperatures in a short period of time. The soil-air partition coefficient $\left(K_{\mathrm{sa}}\right)$ consequently decreases, and PCBs re-volatilise back to the atmosphere and deposit elsewhere by the well known 'grasshopper effect'. In autumn, temperatures decrease again, and $K_{\text {sa }}$ values consequently increase, causing an efficient retention of contaminants. This cycle has been theorised by Dalla Valle et al. (2005), observed in mountain soils by Tremolada et al. (2009a, b) and modelled by Ballabio et al. (2013). These last authors proposed that the discharge kinetics in early summer are rapid because of the higher temperatures and the large dispersion capacity of air, whereas the recharge kinetics in autumn are slow because of the low temperature and the lower air contamination in that season.

Guazzoni et al. (2011) described the seasonal cycle of PCB concentrations in soil by means of six sampling dates from May to October in the same area. The most evident result was that the PCB concentrations peak in soil just after the snowmelt and subsequently decrease rapidly. However, several issues remain to be clarified. (1) Is the recharge phase complete in autumn before the snow mantle, or is it complete in spring just after the snowmelt and before the soil warming? (2) How rapid is the discharge phase in early summer? (3) Are the PCB concentrations in air rather constant during the summer and between the northern and southern aspects? To answer to these questions, a specific sampling campaign was repeated in the same area as that of a previous study (Guazzoni et al. 2011). Soil was sampled in spring under the snow just before melting and later every 7-12 days until the middle of July, and air samples were taken by passive PUF samplers every month from May until November.

\section{Materials and methods}

\section{Soil and air sampling}

Soil and air sampling was performed in 2011 in a pasture area near 2000 m a.s.l. (Andossi plateau) near the Splugen Pass in the central Italian Alps (Fig. S1). Both air and soil samples were collected at two nearby sites having different aspects (north and south). The two aspects were formed by small hills distributed irregularly on the plateau and having a height of approximately $100 \mathrm{~m}$.

Soil samples were collected on 15 April (under the snow before melting), followed by every 7-12 days until 15 July and finally on 14 November (before the winter snow mantle). The complete sampling schedule is reported in Table $\mathrm{S} 1$, and a complete pedological description of the soils of the experimental area is reported in Tremolada et al. (2012). At each sampling site, three sub-samples of soil were taken and separated into two layers: the O layer (organic matter-rich soil, 02-cm depth) and the A1 layer (2-5-cm depth). The three sub-samples from each layer were homogenised (by manual mixing) to reduce the local variability, wrapped in acetone-washed aluminium foil, enclosed in a plastic bag and labelled.

Air sampling was performed every month starting from 11 May until 14 November using PUF disks (14 cm diameter, $1.35 \mathrm{~cm}$ thickness, $365 \mathrm{~cm}^{2}$ surface area, $4.4 \mathrm{~g}$ mass, $207 \mathrm{~cm}^{3}$ volume and $0.0213 \mathrm{~g} \mathrm{~cm}^{-3}$ density) placed in stainless steel domes at two heights at each site: near the ground $(0.15 \mathrm{~m}$ above soil) and at $1.80 \mathrm{~m}$. The disks and stainless steel apparatuses were purchased from Tisch Environmental (Cleves, OH, USA). PUF samplers together with the meteorological apparatus (see next paragraph) were placed inside fences $(5 \mathrm{~m} \times 5 \mathrm{~m})$ to prevent the entry of cows that graze on the plateau (Fig. S1). Deployment times of the PUF disks are reported in Table S2. Both air and soil samples were stored at $-20{ }^{\circ} \mathrm{C}$ until analyses were performed.

\section{Meteorological data}

Meteorological monitoring was performed at three meteorological stations located in the study area. Two were located at the same sites as for sampling (northern and southern sites) and measured the air temperature at $0.15 \mathrm{~m}$ above the soil and the soil temperatures at 0.05 and $0.10 \mathrm{~m}$ depth. The third was located at a plain site between the northern and southern sites (on the top of the hill) and measured the air temperature at $1.80 \mathrm{~m}$ and the soil temperatures at 0.02 and $0.20 \mathrm{~m}$ depth (Fig. S1). The placement of stations and instruments was carried out following the criteria established by the World Meteorological Organisation (WMO 1996). Data were gauged with a time step of $10 \mathrm{~min}$, were periodically transferred to a computer and were elaborated to calculate hourly and daily means for each parameter. Rainfall data were obtained from a nearby meteorological station located approximately $1 \mathrm{~km}$ from the experimental sites (Stuetta meteorological station, $1850 \mathrm{~m}$ a.s.1.). 


\section{Determination of organic carbon}

Each soil sample was analysed for its organic-C content on an elemental analyser (Flash EA 1112 NC soil, Thermo Fisher, Waltham, MA, USA).

\section{PCB quantification}

Fourteen PCB congeners $(18,31+28,52,44,101,149,118$, $153,138,180,170,194$ and 209) were chosen because of their presence in the Italian environment and/or their chlorination degree (from tri- to deca-chlorination classes). Frozen soil samples were lyophilised before extraction. Both soil and air samples were extracted in a soxhlet apparatus with $n$-hexane/ acetone $1: 1$, digested with concentrated sulphuric acid, cleaned on a multilayer silica-florisil column and analysed by GC-MS-MS. A complete description is given in the Supplementary Information (SI).

\section{Statistical analyses}

The software SPSS 18.0 was used to perform the Kolmogorov-Smirnov test to verify the normal distribution of the data. A generalised linear model (GLM) was used to analyse the effect of more factors on a dependent variable, and regression analyses were performed to verify the relationships between variables.

\section{Results and discussion}

\section{PCB levels in air}

PCB amounts in the PUF disks are reported in Table S3. According to the theory of PUF disk samplers (Shoeib and Harner 2002; Harner et al. 2004), during the linear adsorption phase, PUF disk-derived PCB concentrations $\left(\mathrm{pg} \mathrm{m}^{-3}\right)$ can be calculated from the exposure time (days) and the sampling rate $\left(\mathrm{m}^{3}\right.$ day $\left.^{-1}\right)$. In indoor conditions, Shoeib and Harner (2002) calculated sampling rates generally between 2 and $4 \mathrm{~m}^{3}$ day $^{-1}$. The duration of linear adsorption phase depends greatly on $K_{\mathrm{oa}}$ and lasts until $25 \%$ of the PUF-air equilibrium $\left(T_{25}\right)$ is reached (Shoeib and Harner 2002). In field conditions, Harner et al. (2004) demonstrated that chemicals with Log $K_{\mathrm{oa}}>9$ will experience a linear sampling phase for more than 120 days, and during this period, a sampling rate of approximately $3.5 \mathrm{~m}^{3}$ day $^{-1}$ was found. Using depuration compounds, Pozo et al. (2004) calculated a general sampling rate of 2.6 to $4.8 \mathrm{~m}^{3}$ day $^{-1}$ (10 of 12 samples from remote and urban sites in Chile). The other two samples showed a nearly doubled sampling rate. This increase was explained by the extremely windy conditions of these mountain locations, demonstrating the potential wind dependency of the passive air sampling rate. Including these samples, the mean sampling rate becomes $4.78 \pm 2.3 \mathrm{~m}^{3}$ day $^{-1}$. Nevertheless, PUF diskderived concentrations are in good agreement with those from high-volume active samplers, with differences generally within a factor of 2 (Jaward et al. 2004). Considering the short deployment times of this study (Table S2) in relation to the $\mathrm{T}_{25}$ values of the analysed PCBs (Table S4), a constant sampling rate was considered appropriate. The average sampling rate of $4.78 \mathrm{~m}^{3}$ day $^{-1}$, derived by Pozo et al. (2004), was chosen because it includes a variety of sites with very different wind conditions and can therefore reduce the errors coming from this variable. Consequently, PUF disk-derived PCB concentrations in air (Table S5) were calculated based on a $4.78 \mathrm{~m}^{3}$ day $^{-1}$ sampling rate.

The mean concentration in air $\left(35.4 \pm 23.2 \mathrm{pg} \mathrm{m}^{-3}\right.$, Table S5) was almost identical to that measured by Nizzetto et al. (2008) in another Alpine valley $\left(34.6 \pm 10.4 \mathrm{pg} \mathrm{m}^{-3}\right)$ and agrees with background concentrations for rural and remote sites in Europe (Jaward et al. 2004; Van Drooge et al. 2004). GLM analysis reveals that the height above soil $(0.15$ and $1.80 \mathrm{~m}$ ) was highly significant for determining the PCB concentrations in air $(P=0.001$ for the $\Sigma P C B s)$, whereas season and aspect were not $(P=0.21$ and $P=0.12$ for the $\Sigma P C B$, respectively). Marginal means of the $\mathrm{PCB}$ concentrations in the PUF disks at $1.80 \mathrm{~m}$ were nearly double those just above ground ( $0.15 \mathrm{~m}$ above soil), while the contamination fingerprint (relative abundance of the considered congeners) was almost identical (Fig. S2a). A possible concentration gradient in the air above the soil is possible because of growing vegetation and depending on the direction of air-soil fluxes. However, differences in the wind speeds between the two samplers (at 1.80 and $0.15 \mathrm{~m}$ above soil) may also account for the observed concentration difference. In fact, just above soil, herbaceous vegetation and the soil itself greatly decrease the wind speed, which may have substantially reduced the PUF sampling rates and therefore the PUF disk-derived PCB concentrations because a fixed sampling rate was considered. For these uncertainties and because we were interested in air-soil exchanges, we decided to further consider only the results from the PUF disks exposed to the air near the surface ( $0.15 \mathrm{~m}$ above soil). Considering only these data, the calculated mean concentration in air was $20.7 \pm 7.3 \mathrm{pg} \mathrm{m}^{-3}$. GLM analyses of each congener reveal that date and aspect factors were never significant for the lighter congeners (tri- and tetraCBs). However, the north-south difference $(P=0.62)$ and the seasonal concentration trend $(P=0.82)$ for the sum of tri- and tetra-CBs are shown in panels a and c of Fig. S3, respectively. On the contrary, the date was almost always significant for the heavier congeners (from penta- to hepta-CBs). The northsouth difference $(P=0.065)$ and the seasonal concentration trend $(P=0.003)$ for the sum of penta- and hepta-CBs are shown in panels $b$ and d of Fig. S3, respectively. The marginal mean concentrations between the northern and southern sites 
were not significantly different for either the light or heavy congeners, confirming the idea that the air above such a small area is substantially well mixed. On the contrary, during the season, high significant differences were observed for heavier congeners according to the general yearly cycle of the PCB concentration in air (Motelay-Massei et al. 2005; Wania et al. 1998b). The relationship between the concentration in air of the $\Sigma$ PCBs and the mean air temperature (mean of the daily means during the sampling period) was significant only for heavier congeners $\left(R^{2}=0.091, n=12, P=0.34\right.$ and $R^{2}=0.44$, $n=12, P=0.018$ for lighter and heavier congeners, respectively; Fig. S4a, b). The concentrations in air of tri- and tetra-CBs are quite homogeneous during the mountain summer from May to September. This finding was first reported by Nizzetto et al. (2008) based on active air sampling from April until July in a mountain area.

\section{PCB levels in soil}

Concentrations in soil of each PCB congener and of their sum ( $\Sigma$ PCBs) are shown in Table S6. The mean $\Sigma$ PCBs $(1.26 \pm$ $0.73 \mathrm{ng} \mathrm{g}^{-1}$ dry weight (d.w.)) is slightly lower than those obtained in the same area in $2007\left(1.63 \pm 1.27 \mathrm{ng} \mathrm{g}^{-1}\right.$ d.w., Tremolada et al. 2009a) and in $2008\left(1.51 \pm 1.12 \mathrm{ng} \mathrm{g}^{-1}\right.$ d.w., Guazzoni et al. 2011). These data depict a decreasing PCB trend of $7 \%$ year $^{-1}$. The general contamination level corresponds to that of background soils (Meijer et al. 2003) and is well below the Italian legal limit for agricultural soils (60 ng g $^{-1}$ d.w., DLgs 152/06). The most interesting result of these soil contamination data came from the PCB fingerprint. Figure S2c, d shows an almost identical fingerprint of the two soil layers (O and A1) characterised by very low amounts of tri- and tetra-CBs and very high abundances of hexa- and hepta-CBs, as expected. The surprising result is an unexpected high abundance of CB-209. Considering the abundances of CB-153, CB-138 and CB-180 (sum near $55 \%$ ) according to their persistence, accumulation potential in soil and congener abundance in commercial PCB mixtures most commonly used in Italy and Europe (Frame et al. 1996; Breivik et al. 2002), the abundance of CB-209 is completely unexplainable based on the commercial PCB mixtures. In addition, its volatility is too low for gas-phase atmospheric transport, but its detection in soil was observed very clearly in every soil sample; all analytical checks confirmed the compound identification (Fig. 1). In addition, CB-209 was found only in soil, not in the air, vegetation or cow's milk from the same area (Tremolada et al. 2014). The origin of this congener in this mountain environment is difficult to explain. The Caffaro chemical plant near Brescia in Italy, which was the main producer of PCB mixtures in Italy (near 31,000 $t$ total), also produced a commercial product (Fenclor DK) containing only technical-grade CB-209 (nearly 180 t/year) from 1972 until 1977 (de Voogt and Brinkman 1989). This chemical
Fig. 1 TIC-chromatogram with enlarged the portion including the peak of CB-209 (RT=38.96) and abundance of specific daughter ions of CB209 in standard (a), in blank (b) and in a soil sample from Andossi plateau (c)

plant, which is approximately $150 \mathrm{~km}$ away from the study area, may represent a regional point source for this congener. Unfortunately, current studies on PCB contamination in nearby soils have mainly focused on dioxin-like PCBs and have not included CB-209 (e.g. Turrio-Baldassarri et al. 2007); new studies are therefore necessary. Other possible point sources are incinerators or metal industry plants in which the burning of plastic materials in the presence of chlorine may produce stable chlorinated organic compounds such as PCDDs and PCDFs (e.g. Fu et al. 2012; Van Caneghem et al. 2014; Esposito et al. 2014). Another possible specific source of CB-209 is the presence of this congener in several chemical pigments (Hu and Hornbuckle 2010; ETAD 2011; Anezaki and Nakano 2014). Hu and Hornbuckle (2010) detected CB209 as an impurity at nearly $40 \%$ of analysed pigments, and Anezaki and Nakano (2014) reported the presence of CB-209 in pigments at a concentration of $2.3 \mathrm{mg} \mathrm{kg}^{-1}$ and also measured it in indoor air. The presence of this congener in air and its particle-phase atmospheric transport can explain the occurrence of this congener far from source areas. Long-range atmospheric transport of decabromodiphenyl ether (BDE-209) was explained by the transport of this compound sorbed onto aerosol particles (Gouin et al. 2006). CB-209 has generally not been considered in the past because of its absence in major commercial PCB mixtures; however, data from these works highlight the necessity of considering it as a 'new' contaminant of concern. The deliberate production of CB-209 in Fenclor DK and its formation as a by-product during waste incineration, in the metal industry and in the chemical manufacturing of organic chemicals such as paint pigments may represent consistent contamination sources. The Italian Alps might be particularly interesting because of their proximity to the Caffaro site.

\section{Seasonal trend of PCBs in soil}

The seasonal trend of PCBs in soil was analysed from April until November. Soil concentrations were normalised on the basis of their organic carbon content to avoid differences among samples due to the organic matter fraction. As expected, the relationship between organic carbon content and PCB concentrations on a dry weight basis was significant $(P<0.001)$ but with a low regression coefficient $\left(n=44 ; R^{2}=\right.$ 0.28 ) because of the other variables considered in the experimental plan: soil layers, mountain side in relation to the sun exposure and different sampling dates (Table S1). The GLM of the organic carbon-normalised PCB concentrations (ng $\mathrm{g}^{-1}$ OC) revealed a highly significant effect of the layer and aspect 

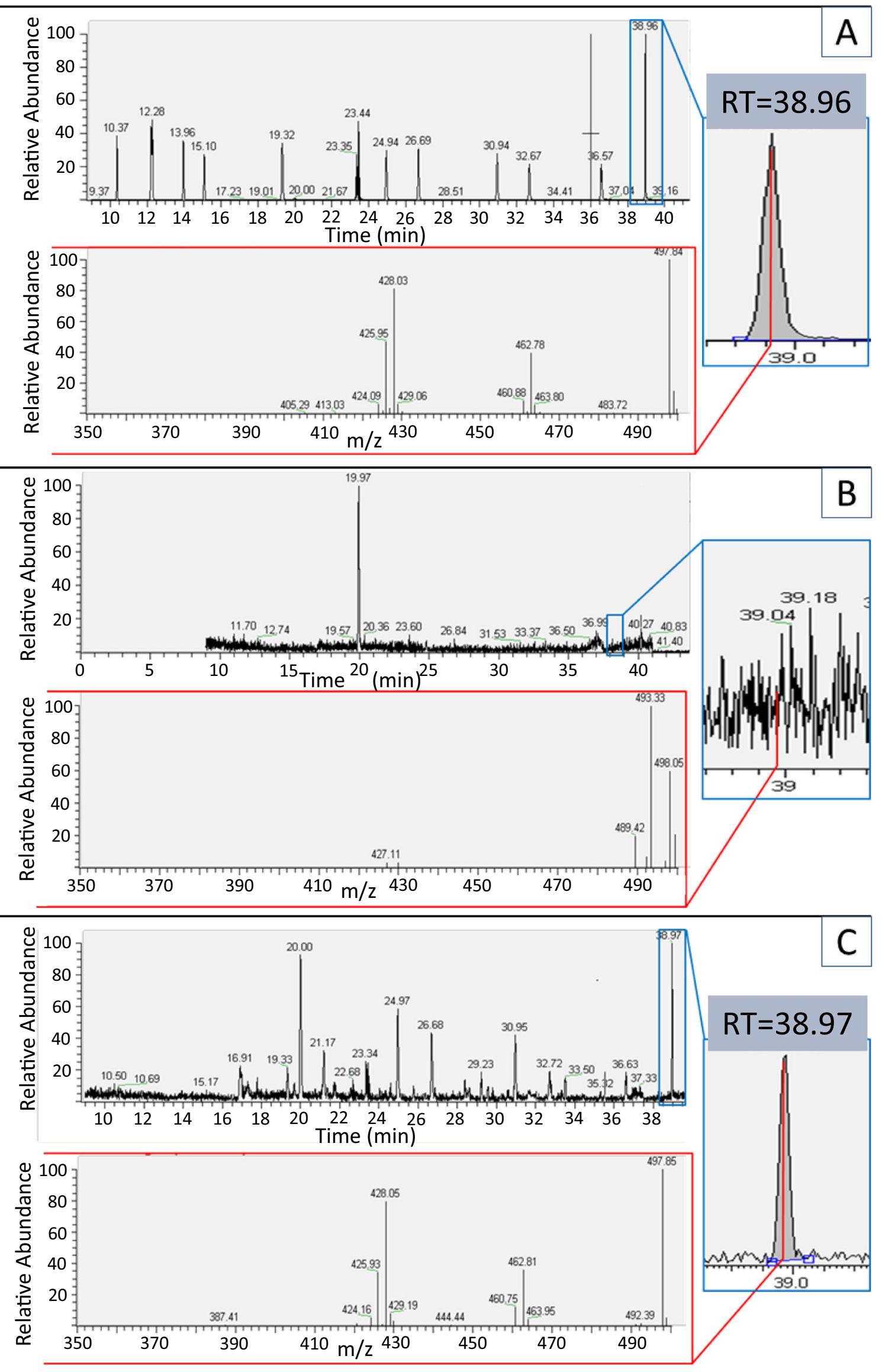
( $P<0.001$ for many congeners and for $\Sigma$ PCBs $)$ and a nonsignificant effect of date $(P=0.085$ for $\Sigma P C B s)$. The layer effect is reported in Fig. S5 and can be interpreted, at least partially, as depending on the quality of the organic matter. In fact, the surface soil layer has a higher fraction of humin, which has a higher affinity for hydrophobic contaminants than the other humic fractions (Tremolada et al. 2012). The effect of aspect and date was analysed better by the GLM considering the two layers separately. Figure 2 shows the marginal means of the $\Sigma$ PCBs concentrations at the north and south sites for the two soil layers (Fig. 2a, c) and the single data at the north and south sites for each sampling date and soil layer (Fig. 2b, d). The O layer (0-2 cm depth) showed a greater north vs. south concentration difference $(P=0.002)$ but no significant seasonal trend $(P=0.64)$, whereas the A1 layer (2-5 cm depth) showed a lower north/south concentration gradient that was still significant $(P=0.02)$ and a highly significant seasonal trend $(P<0.001)$. The north/south enrichment factor in soil depends on the temperature gradient between the northern and southern sites (Tremolada et al. 2009a; Guazzoni et al. 2011). This temperature gradient was measured in the study area both in soil (Fig. 3) and in air (Fig. S6). Temperatures in air were quite similar at this small spatial scale, while soils experienced a higher temperature gradient between the northern and southern sites because of the effect of direct solar radiation. The north/south temperature gradient is also expected to become higher at the beginning and at the end of the summer season because the azimuth of the sun is lower and the shadow effect of reliefs is higher in these periods. Daily mean temperatures in the northern and southern site soils confirm this effect (Fig. 3). Therefore, the north/south PCB concentration gradient is expected to be greater at the beginning of the season, to converge to similar values in the middle of the summer and to finally diverge again at the end of the season. This differential seasonal trend, depending on the aspect, can be recognised in Fig. 2b, d.

Differences between the seasonal trends in the two soil layers (Fig. 2b, d) can be interpreted considering that the surface layer $(0-2 \mathrm{~cm})$ is in direct contact with air and is therefore more dependent on short-term climatic conditions. This feature justifies a higher variability of the PCB concentrations among the sampling dates and between the northern and southern sites and a more irregular seasonal trend (Fig. 2b). On the contrary, the subsurface layer $(2-5 \mathrm{~cm})$ is protected from direct solar radiation and from direct PCB scavenging by precipitation events. This partial isolation justifies a more regular seasonal trend with a lower variability among the sampling dates and between the northern and southern sites (Fig. 2d). Subsurface soil can be considered more dependent on medium-term climatic conditions (e.g. those of weeks).

The experimental plan was specifically designed to clarify the initial recharge phase after the snowmelt and the later discharge phase of the previously accumulated contaminants. From the data (Fig. 2b, d), the recharge phase in 2011 appears to be mostly completed in autumn, especially at the northern site, which experienced the higher temperature decrease in autumn because of an absence of direct solar radiation (in this period, the daily mean temperature gradient between the
Fig. 2 Marginal means of the $\Sigma$ PCBs concentrations in North and South soils from Andossi plateau in function to aspect and date in the $\mathrm{O}$ layer $(\mathbf{a}, \mathbf{b})$ and in the A1 layer (c, d). Bars refer to $95 \%$ confidence interval of the marginal means
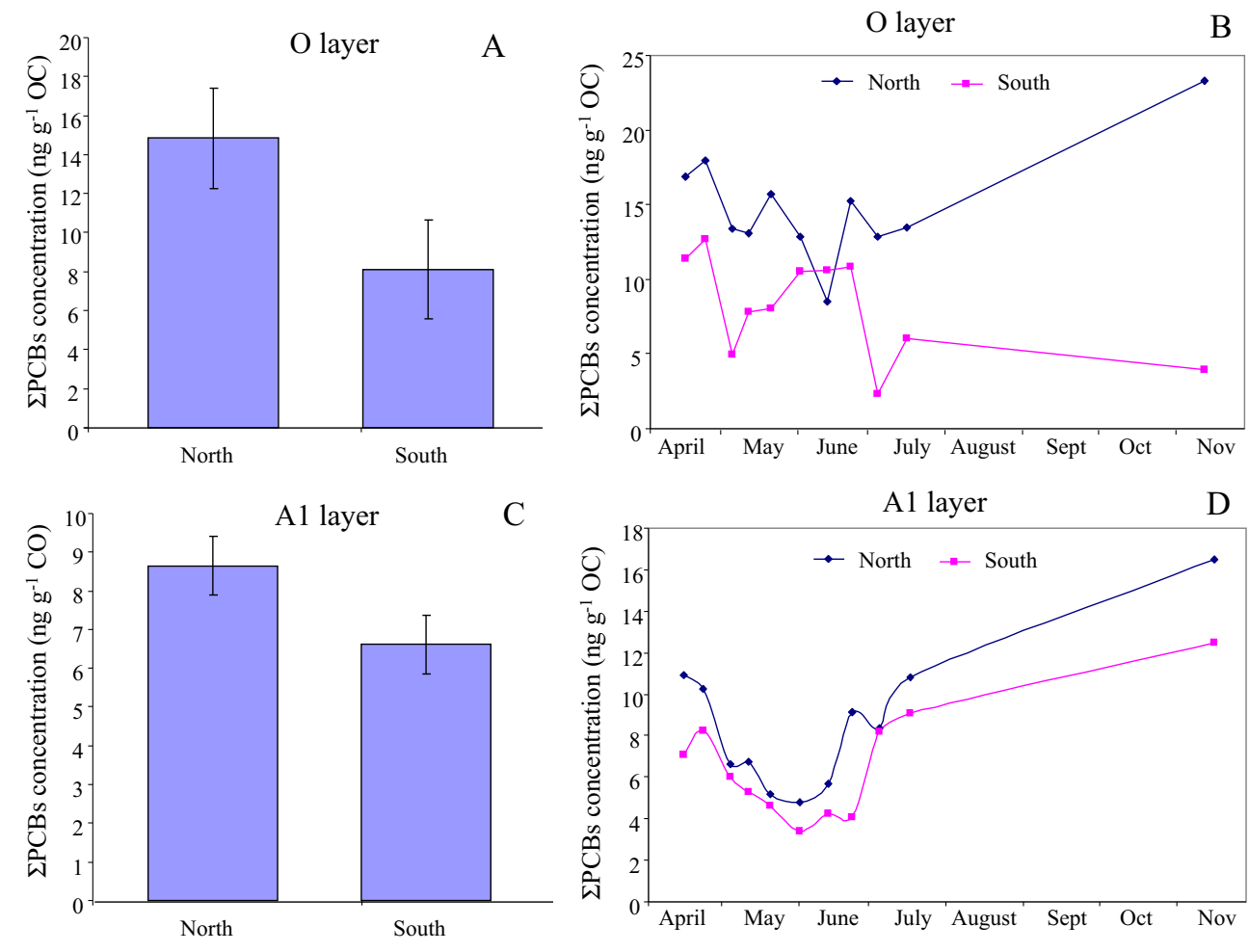


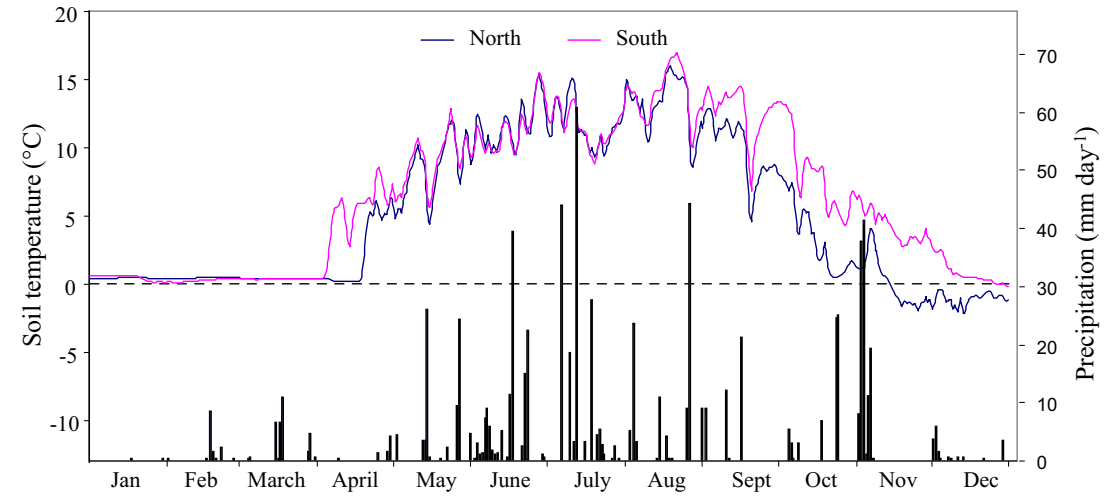

Fig. 3 Daily mean temperatures of soil at $5 \mathrm{~cm}$ depth in the North and South sites of the Andossi plateau during 2011 (left axis), and daily cumulative precipitations taken from the nearest station of Stuetta (right axis). Soil temperatures in the north site were missed from 04 May 2011 until 22 May 2011. During this period (18 days), soil temperatures in the

north site were obtained by the regression equation between the daily mean temperatures in the South and North sites, considering 1 week before and after the period of missing data $(y=1.1389 x-1.9941 ; n=14$; $R^{2}=0.93$, where $x$ and $y$ are the temperatures in the South and North sites, respectively)

northern and southern site soils at a depth of $5 \mathrm{~cm}$ reached even $5.5^{\circ} \mathrm{C}$, Fig. 3). Conversely, the southern site, receiving direct solar radiation in November, experiences higher temperatures, especially in the surface layer, and the PCB concentration recharge is consequently delayed (Fig. 2b). For both layers, the last sampling at the northern site revealed higher PCB concentrations than those found in the beginning (interannual differences are expected and depend on the specific climate conditions of the year).

The second sampling (just after the snowmelt) shows higher PCB concentration than those found in the first sampling (just before the snowmelt), with the exception of the A1 layer at the northern site (Fig. 2d). The contribution of the melting waters and the initial phase in which the soils are still cold (high $K_{\text {sa }}$ values) give an initial additional load of contaminants to the soils. Later, the PCB concentrations decrease because of the soil temperature increase. As temperatures increase, $K_{\mathrm{sa}}$ values decrease, and therefore, soil concentrations in both layers and aspects decrease by means of volatilisation of the equilibrium-exceeding PCB fraction (Fig. 2b, d). The emissions rate and half-life for the $\Sigma \mathrm{PCBs}$ in the $\mathrm{A} 1$ layer between T2 and T3 were 0.035 and 20 day $^{-1}$, respectively, using the exponential model $C_{1}=C_{0} \cdot e^{-k t}$. These values are almost identical to those calculated by Guazzoni et al. (2011) in the same area $\left(0.033\right.$ day $^{-1}$ and $t^{1 / 2}$ of 21 days).

The temperature-dependent interpretation of the seasonal trend of the PCB concentrations in soil agrees with that of Hippelein and McLachlan (2000) and Ballabio et al. (2013) and can be verified by comparing the PCB concentrations in soil and their temperature-specific $K_{\mathrm{sa}}$ values. Including the effect of temperature in the equation suggested by Hippelein and McLachlan (1998), we can obtain specific $K_{\mathrm{sa}}$ values for each congener on each sampling date.
Equation (1) includes the effect of temperature in the relationship proposed by Hippelein and McLachlan (1998):

$K_{\mathrm{sa}}=0.411 \cdot f_{\mathrm{oc}} \cdot \rho_{\mathrm{s}} \cdot K_{\mathrm{oa}} \cdot \exp \left[-\frac{\Delta U_{\mathrm{oa}}}{R} \cdot\left(\frac{1}{T}-\frac{1}{298.15}\right)\right]$

where

$K_{\text {sa }} \quad$ Soil-air partition coefficient

$f_{\text {oc }} \quad$ Organic carbon content of the dry soil in units of gram of organic carbon per gram of dry soil $\left(f_{\text {oc }}\right.$ data are reported in Table S6)

$\rho_{\mathrm{s}} \quad$ Density of the dry soil in units of kilogram per cubic decimetre; the soil density of each sample was calculated with the empirical relationship $\rho_{\mathrm{s}}=1.1516$. $\exp \left(-6.1 \cdot f_{\text {oc }}\right)$ obtained from 32 surface soil samples $(0-10 \mathrm{~cm}$ depth $)$ from the same experimental area $\left(n=32 ; R^{2}=0.75\right)$

$K_{\text {oa }} \quad$ Octanol-air partition coefficient at $25^{\circ} \mathrm{C}\left(K_{\text {oa }}\right.$ data are reported in Table S4)

$\Delta U_{\text {oa }} \quad$ Internal energy of the phase transfer between octanol and air in units of kilojoule per mole $\left(\Delta U_{\text {oa }}\right.$ data are reported in Table S4)

$R \quad$ Gas constant $\left(0.008314 \mathrm{~kJ} \mathrm{~mol}^{-1} \mathrm{~K}^{-1}\right)$

$T \quad$ Mean soil temperature at $5 \mathrm{~cm}$ depth in units of Kelvin $\left(273.5+{ }^{\circ} \mathrm{C}\right)$ for the time period among sampling (7-12 days), as reported in Table S1.

The 7-12-day period corresponds to the time interval among sampling, and it was chosen considering the relatively fast exchange kinetics between soil and air (Guazzoni et al. 2011). Longer periods would eventually include temperature conditions too far in time to substantially affect the PCB concentrations in soils, and, conversely, shorter periods would not be sufficient for substantially changing the concentrations measured a few days later. Mean temperatures calculated from 
7 to 12 days before each sampling are not much different from the 7-day mean temperatures (homogeneous interval before each sampling), but they were preferred because they include all of the time intervals among the samples (excluding the first and last samples for which a fixed time interval of 7 days was chosen). Mean soil temperatures over several days smooth the variability among days and the air temperature fluctuations by the soil properties. However, the 7-12-day mean temperatures would have loosened the eventual effect of climatic conditions that were extreme in intensity but short in duration, losing part of the variability explanation.

As an example, Fig. 4a reports the relationship between CB-153 concentrations in the A1 layer and their logarithmic temperature-specific $K_{\mathrm{sa}}$ values. Most of the data seem to follow a direct linear relationship, but the data points circled by a dotted line have rather high concentrations in relation to their $K_{\text {sa }}$ values (sampling in July). This month is normally characterised by high soil temperatures, but in 2011, it was characterised by a relatively low air temperature and very high precipitation (Figs. S6 and 3, respectively) compared to the 30-year means (SISS 2007). The effect of precipitations on POP concentrations in soils has been previously proposed (Davidson et al. 2003; Tremolada et al. 2007). Here, it can be quantitatively verified by comparing the $K_{\mathrm{sa}}$-normalised PCB concentrations with the amount of precipitation that has fallen before each sampling date (Table S1). The cumulative amount of precipitation since the previous sampling was considered for all sampling dates, with the exception of the first and last samplings for which a period of 7 days before sampling was chosen. Table 1 reports the statistical data of the relationship between the $K_{\mathrm{sa}}$-normalised PCB concentrations and precipitation (linear interpolation was chosen instead of exponential because of the best fit). Figure $4 \mathrm{~b}$ shows the case of CB-209 in the $\mathrm{A} 1$ layer as an example because of the high $R^{2}$ value and the attention to this congener. All congeners for which a complete set of data were available (from CB-101 to CB-209) showed a significant relationship between their concentration and the precipitation amount before sampling (7-12 days before) in both layers. Also in this case, the entire interval between samplings was chosen instead of a fixed interval (e.g.
Fig. 4 Relationship between CB153 concentrations in soil and temperature-specific $K_{\mathrm{sa}}$ values (a) and relationship between $K_{\mathrm{sa}^{-}}$ normalised concentrations of $\mathrm{CB}$ 209 and cumulative precipitation before each sampling date (b)
A

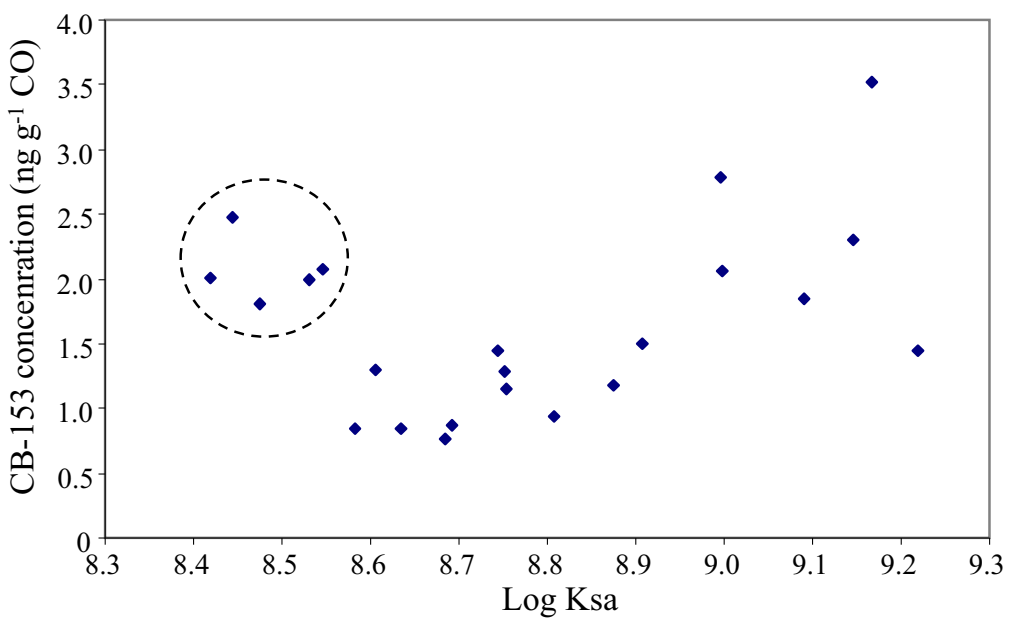

$\mathrm{B}$

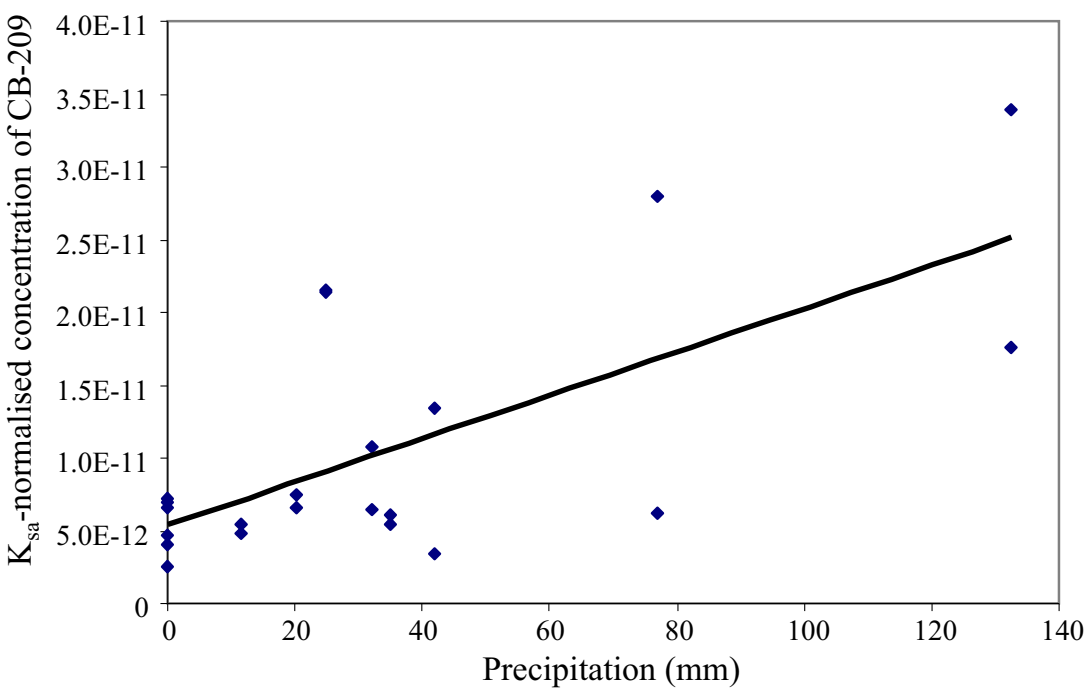


Table 1 Statistical parameters of the linear regression of the $K_{\mathrm{sa}^{-}}$ normalised concentrations in soil of several PCB congeners in function of precipitations

\begin{tabular}{llrllllll}
\hline \multirow{2}{*}{ PCB congener } & \multicolumn{3}{l}{ O layer } & & & \multicolumn{2}{l}{ A1 layer } \\
\cline { 2 - 5 } \cline { 6 - 8 } & $R^{2}$ & $F_{1 ; 20}$ & $P$ & & $R^{2}$ & $F_{1 ; 20}$ & $P$ \\
\hline 101 & 0.41 & 13.72 & $0.001^{* *}$ & & 0.36 & 11.26 & $0.003^{* *}$ \\
149 & 0.39 & 12.72 & $0.002^{* *}$ & & 0.40 & 13.57 & $0.001^{* *}$ \\
118 & 0.30 & 8.73 & $0.008^{* *}$ & & 0.47 & 17.84 & $<0.001^{* * *}$ \\
153 & 0.39 & 12.76 & $0.002^{* *}$ & & 0.41 & 14.03 & $0.001^{* *}$ \\
138 & 0.37 & 11.97 & $0.002^{* *}$ & & 0.45 & 16.31 & $0.001^{* *}$ \\
180 & 0.33 & 9.92 & $0.005^{* *}$ & & 0.39 & 12.75 & $0.002^{* *}$ \\
170 & 0.36 & 11.33 & $0.003^{* *}$ & & 0.43 & 14.80 & $0.001^{* *}$ \\
194 & 0.22 & 5.48 & $0.030^{*}$ & & 0.39 & 12.50 & $0.002^{* *}$ \\
209 & 0.28 & 7.87 & $0.011^{*}$ & & 0.46 & 16.75 & $0.001^{* *}$ \\
\hline
\end{tabular}

$* P<0.05 ; * * P<0.01 ; * * * P<0.001$

7 days). The $\mathrm{A} 1$ layer showed higher $R^{2}$ values than the $\mathrm{O}$ layer, confirming the higher conservative properties of this layer in comparison to the $\mathrm{O}$ layer, with respect to $\mathrm{PCB}$ contamination.

\section{Soil-air partition quotients $\left(Q_{\mathrm{sa}}\right)$}

$Q_{\text {sa }}$ represents the ratio between the soil and air concentrations for a specific soil in a given time (Meijer et al. 2003), and $K_{\text {sa }}$ represents the same ratio at equilibrium (Hippelein and McLachlan 1998). Changes in soil properties (temperature) or air contamination levels keep $Q_{\text {sa }}$ values far from equilibrium (corresponding $K_{\mathrm{sa}}$ ), and the exchange fluxes between the soil and air try to fill the gap between the actual and equilibrium conditions. Generally, concentrations in soil are relatively stable, while those in air are not, making time- and space-specific $Q_{\mathrm{sa}}$ calculations quite difficult. To overcome these difficulties, mean concentrations in air over long periods are considered. Alternatively, data from long sampling periods (such as those obtained by passive air samplers) are considered good estimations of the mean concentrations in air over the deployment period (Shoeib and Harner 2002; Harner et al. 2004, 2006; Jaward et al. 2004; Motelay-Massei et al. 2005) and therefore suitable for $Q_{\mathrm{sa}}$ calculations. In this study, for the sampling dates in which PCBs were measured above the LOQ in both soil and air, $Q_{\mathrm{sa}}$ values were calculated from the ratio between the $\mathrm{PCB}$ concentrations in the $\mathrm{O}$ layer (in direct contact with air) and those in air, both with units of picogram per cubic metre. Concentrations in soil in nanogram per gram dry weight can be transformed to picogram per cubic metre by a factor of $10^{9}$, and the soil density $\left(\mathrm{kg} \mathrm{L}^{-1}\right)$ can be calculated as in Eq. (1). These experimental $Q_{\mathrm{sa}}$ values can be compared with the corresponding $K_{\mathrm{sa}}$ values calculated for each PCB congener using Eq. (1).

The relationship between the measured $Q_{\mathrm{sa}}$ and predicted $K_{\mathrm{sa}}$ both in logarithm is reported in Fig. 5. Linear regression $\left(y=0.78 \times x+0.81 ; n=96 ; R^{2}=0.79\right)$ shows a slope lower than 1 , meaning that a higher $K_{\text {oa }}$ corresponds to a greater difference between the measured and predicted values. Congener 180 had the highest $\log K_{\text {sa }}(9.49 \pm 0.22)$ value and a mean $\log Q_{\text {sa }}$ value (7.96 \pm 0.37$)$ no different from that of congener 138 or 153 (7.92 \pm 0.33 and $7.85 \pm 0.39$, respectively). The linear relationship between the measured $\log Q_{\mathrm{sa}}$ and predicted $\log K_{\mathrm{sa}}$ appears flat above a $K_{\mathrm{sa}}$ value of 9. For a $\log K_{\mathrm{sa}}$ of 8 , the difference between the measured and predicted values is approximately $1 \mathrm{Log}$ unit. The overestimation of the calculated $Q_{\text {sa }}$ values likely derives from an overestimation of the gasphase concentrations in air. In fact, PUF disks are able to accumulate both gas-phase contaminants and contaminants adsorbed to particles that arrive at the disk by means of the air flow (gas- and particle-wet deposition are excluded); therefore, air concentrations determined by passive air sampling are an overestimation of the gas-phase concentration, especially for compounds having high $K_{\mathrm{oa}}$ values and under low
Fig. 5 Relationship between predicted $K_{\mathrm{sa}}$ values and calculated $Q_{\mathrm{sa}}$ values in logarithm of the different PCB congeners

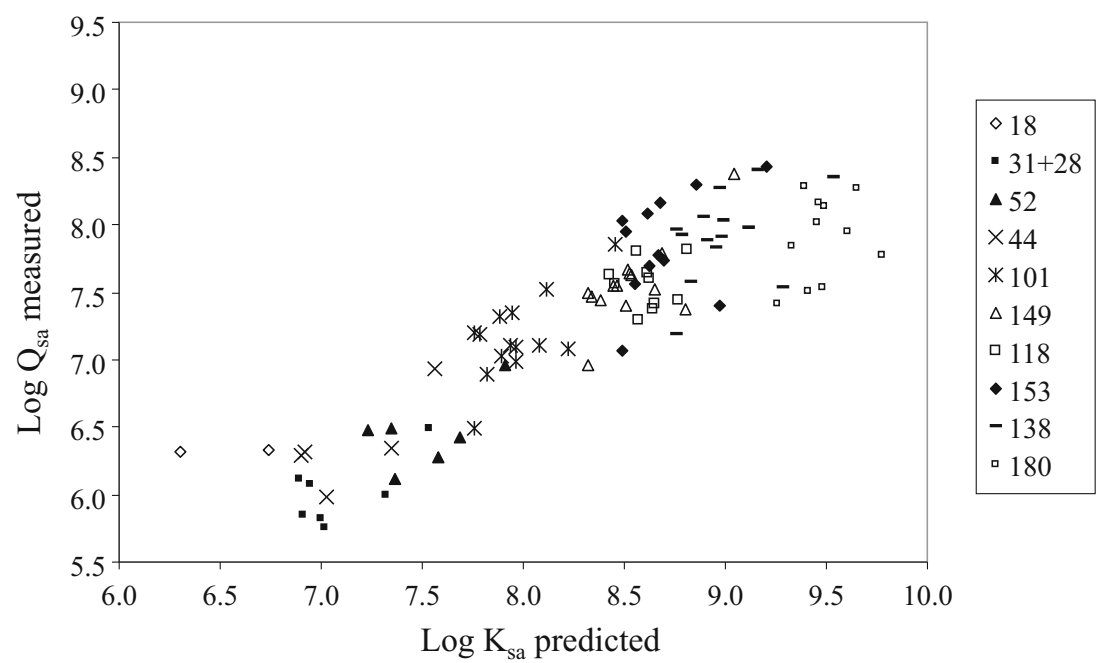


temperature conditions. On the contrary, $K_{\mathrm{sa}}$ refers only to the gas-phase equilibrium. Therefore, calculations based on an overestimation of the gas-phase air concentrations are expected to give a lower $Q_{\mathrm{sa}}$ than predicted. By this interpretation, the $Q_{\mathrm{sa}}$ vs. $K_{\mathrm{sa}}$ discrepancies are expected to be $K_{\mathrm{oa}}$-dependent, as actually observed.

To avoid a misleading interpretation of the soil-air exchanges, the fugacities in air and soil were calculated using the measured concentrations as usual and, for soil fugacity, using the mean $Q_{\mathrm{sa}}$ values instead of the predicted $K_{\mathrm{sa}}$ values. Mean calculated $Q_{\mathrm{sa}}$ values for each congener are able to neutralise the effect of the overestimation of the gas-phase concentrations in air due to the particle-phase contribution in the PUF disk-derived concentrations. Moreover, mean calculated $Q_{\text {sa }}$ values for the entire considered season are able to represent an intermediate condition 'near' the soil-air equilibrium because these mean calculated $Q_{\mathrm{sa}}$ values include periods of net volatilisation (higher fugacity in soil than in air, e.g. middle of summer) and periods of net deposition higher (fugacity in air than in soil, e.g. late autumn). Therefore, (using mean $Q_{\mathrm{sa}}$ values to calculate fugacity in soil instead of predicted $K_{\mathrm{sa}}$, we obtain a $Q_{\mathrm{sa}}$-derived fugacity (Eq. 2) that is different from the fugacity calculated from the predicted soil-air equilibrium ( $K_{\mathrm{sa}}$-derived fugacity). To differentiate the $Q_{\mathrm{sa}}$-derived fugacity from the $K_{\mathrm{sa}}$-derived value, we call the former $f_{\mathrm{s}}{ }^{\prime}$. By this definition, $f_{\mathrm{s}}{ }^{\prime}$ is a fugacity value relative to the mean ratio between the soil-air concentrations experimentally measured in the experimental (area (mean $Q_{\mathrm{sa}}$ values), and it therefore takes into account the specific conditions of the area and the particle-phase contribution present in the PUF diskderived concentrations.

$f_{\mathrm{s}}^{\prime}=\frac{C_{\mathrm{s}}}{Z_{\mathrm{s}}}=\frac{C_{\mathrm{s}} \cdot R \cdot T}{Q_{\mathrm{sa}}}$

where

$f_{\mathrm{s}}^{\prime} \quad$ Relative fugacity in soil in pascal for each sampling site and each deployment period in which both soil and air sampling were available

$C_{\mathrm{s}} \quad$ Measured concentration in soil in mole per cubic metre for each sampling site and each deployment period in which both soil and air sampling were available

$Z_{\mathrm{s}} \quad$ Fugacity capacity of soil in mole per cubic metre per pascal for each sampling site and each deployment period in which both soil and air sampling were available

$R \quad$ Gas constant $\left(8.314 \mathrm{~Pa} \mathrm{~m}^{3} \mathrm{~mol}^{-1} \mathrm{~K}^{-1}\right.$ )

$T \quad$ Mean air temperature at $15 \mathrm{~cm}$ above the ground in units of Kelvin $\left(273.5+^{\circ} \mathrm{C}\right)$ for each sampling site and each deployment period in which both soil and air sampling were available (data are reported in Table S2)

$Q_{\text {sa }} \quad$ Mean of all $Q_{\text {sa }}$ values in the O layer calculated for each sampling site and each deployment period in which both soil and air sampling were available.

The fugacity in air, calculated by Eq. (3), also takes into account the particle-phase contribution present in the PUF disk-derived concentrations $\left(C_{\mathrm{a}}\right)$. For this reason, the fugacity in air, calculated by Eq. (3), must be intended as a 'relative
Fig. 6 Mean relative fugacity ratios in function to $\mathrm{PCB}$ congeners and sampling date in the North and South sites and in the $\mathrm{O}$ and $\mathrm{A} 1$ layers. Bars refers to the interval \pm the standard error
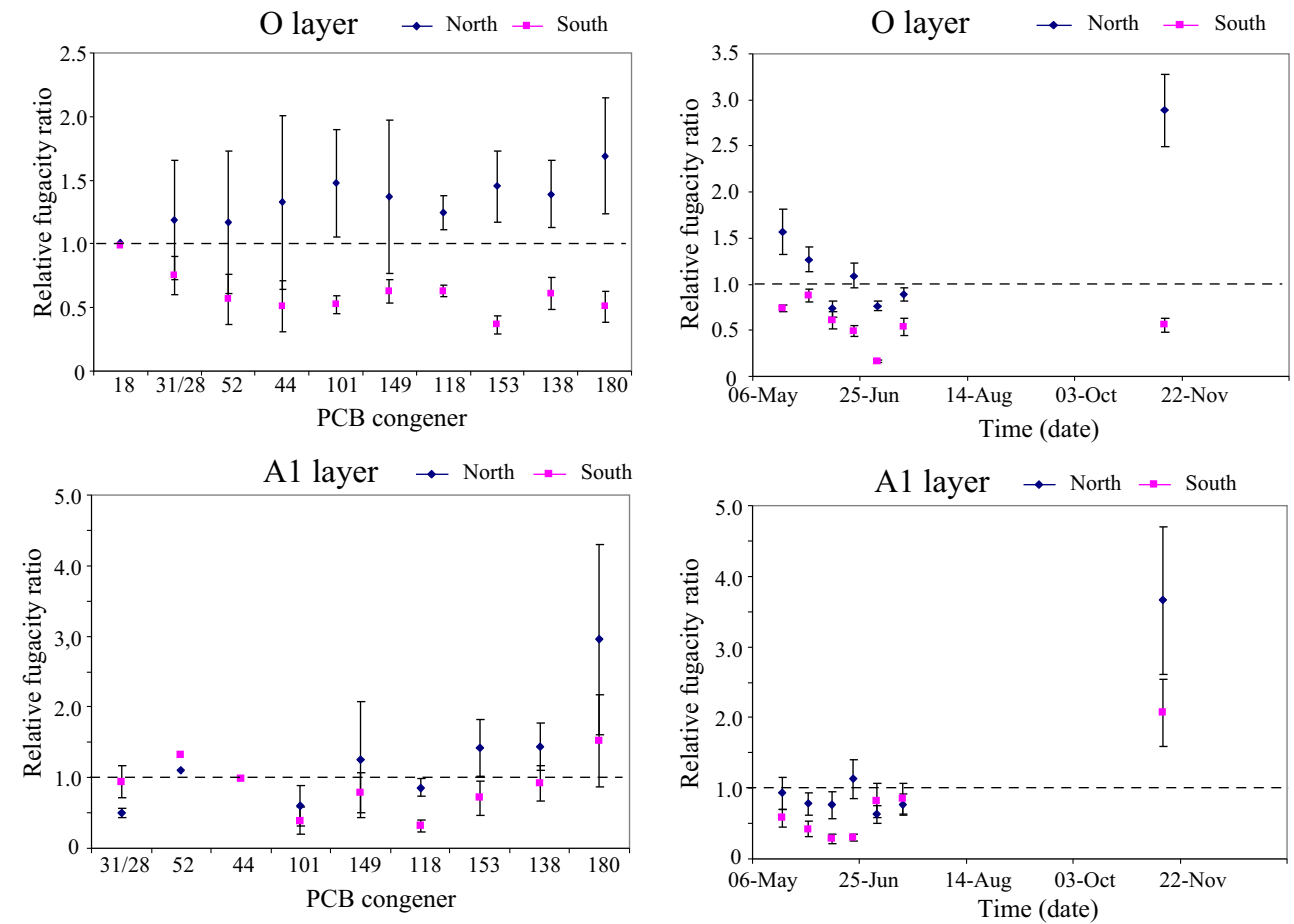
fugacity' because it is 'relative' to the PUF disk-derived concentrations $\left(C_{\mathrm{a}}\right)$ and is therefore defined $f_{\mathrm{a}}$ '.

$f_{\mathrm{a}}^{\prime}=\frac{C_{\mathrm{a}}}{Z_{\mathrm{a}}}=C_{\mathrm{a}} \cdot R \cdot T$

where

$f_{\mathrm{a}}{ }^{\prime} \quad$ Relative fugacity in air in pascal for each sampling site and each deployment period in which both soil and air sampling were available

$C_{\mathrm{a}}$ Measured concentration in air in mole per cubic metre for each sampling site and each deployment period in which both soil and air sampling were available

$Z_{\text {a }} \quad$ Fugacity capacity of air in mole per cubic metre per pascal for each sampling site and each deployment period in which both soil and air sampling were available $R \quad$ Gas constant $\left(8.314 \mathrm{~Pa} \mathrm{~m}^{3} \mathrm{~mol}^{-1} \mathrm{~K}^{-1}\right.$ )

$T$ Mean air temperature at $15 \mathrm{~cm}$ above the ground in units of Kelvin $\left(273.5+{ }^{\circ} \mathrm{C}\right)$ for each sampling site and each deployment period in which both soil and air sampling were available (data are reported in Table S2).

Using $C_{\mathrm{a}}$ and the mean calculated $Q_{\mathrm{sa}}$ values (Eqs. 3 and 2, respectively), the 'relative fugacities' in air and in soil take into account both particle-phase contributions of the PUF disk-derived concentrations. Therefore, the relative fugacities in air are comparable to the relative fugacities in soils, and their ratios can be called 'relative fugacity ratios' $\left(\mathrm{rfr}=f_{\mathrm{s}}\right.$ ') $f_{\mathrm{a}}{ }^{\prime}$ ). A simple ratio was preferred to the commonly used fugacity fraction ( $\mathrm{ff}=f_{\mathrm{s}} /\left[f_{\mathrm{s}}+f_{\mathrm{a}}\right]$, e.g. Li et al. 2010) because it is better able to emphasise the dimension of the shift from the supposed equilibrium.

Relative fugacity ratios were calculated for each sampling site and each deployment period in which both soil and air sampling were available (T6, T8, T10 and T16). For deployment times in which two soil samples were analysed (T6, T8 and T10), two different fugacity ratios were calculated for each site using the two soil concentrations and just one air concentration. A total of 14 relative fugacity ratios were calculated for each congener with detectable levels in both soil and air.

Figure 6 shows the relative fugacity ratios at the two sites (north and south) as a function of the different congeners (panels a and c of Fig. 6 for the $\mathrm{O}$ and A1 layers, respectively) and the sampling date (panels $\mathrm{b}$ and $\mathrm{d}$ of Fig. 6 for the $\mathrm{O}$ and A1 layers, respectively). For both compound- and datefugacity analyses, the northern site has a relative fugacity ratio generally higher than 1 because the lower temperatures at this site are able to retain the arrived contaminants over the mean $Q_{\text {sa }}$ value (which includes both the northern and southern sites). On the contrary, southern soils, being subject to the same wet deposition fluxes but higher temperatures (during sunny days), are able to release back the contaminants more efficiently than the northern soils. This is evident especially for the less volatile compounds. Looking at the seasonal trend (Fig. 6b, d), the northern soils exceeded the mean $Q_{\mathrm{sa}}$ values in the O layer both in May and November. In May, only the northern soils show an ongoing discharge phase (this phase ended previously in the southern soils). In November, only the northern soils are able to retain the arrived contaminants (soil temperatures are also low on sunny days because of the shadow effect of the mountain side). In November, the A1 layer of both the northern and southern soils is able to retain the contaminants transported to soils over the mean $Q_{\mathrm{sa}}$ value. The A1 layer is protected by a temporally limited volatilisation phenomena that appears to occur only in the O layer of the southern aspect.

\section{Conclusions}

Unexpectedly high concentrations of CB-209 were detected in these mountain soils. The present findings and the few papers that report measurable CB-209 concentrations in environmental samples highlight the possible threat of this highly persistent contaminant. Sources of CB-209 are still incompletely evaluated, as well as its possible ecotoxicological risk. For these reasons, new research on this congener is highly recommended, together with the continuous monitoring of PCBs in general.

In addition to this above-mentioned unexpected result, the present paper provides additional evidence of a seasonal cycle of the PCB concentrations in soil, furnishing some details of the times, causes and modalities of small spatial- and short temporal-scale distribution phenomena:

- PCB concentrations in air over the experimental area do not show spatial variability between the northern and southern sites. Air can be considered horizontally well mixed.

- Concentrations in air of more volatile PCBs (tri- and tetra-CBs) are nearly constant during the mountain summer (from June to September), while those of the less volatile PCBs (penta- and hepta-CBs) exhibit a typical parabolic trend.

- PCB concentrations in soil change spatially and seasonally in the experimental area, even if the area is very small; the spatial variability depends on the microclimatic features (northern vs. southern aspects) or the soil characteristics, while the seasonal variability depends on both the temperature and precipitation events. This paper provides highly significant relationships between PCB concentrations normalised to temperature and precipitation amounts ('precipitation effect').

- The relative fugacity ratios highlight the evident accumulation phase in autumn (recharge phase), especially at the northern site and in the A1 layer. The snow mantle postpones soil-air exchanges until the next warm season. 
Acknowledgments We would like to warmly thank Mr. Donnino Della Bella and 'Consorzio Alpe Andossi' for their hospitality and contributions in setting up the sampling sites and for providing useful information.

\section{References}

Anezaki K, Nakano T (2014) Concentration levels and congener profiles of polychlorinated biphenyls, pentachlorobenzene, and hexachlorobenzene in commercial pigments. Environ Sci Pollut Res 21:9981009

Ballabio C, Guazzoni N, Comolli R, Tremolada P (2013) Highly spatially- and seasonally-resolved predictive contamination maps for persistent organic pollutants: development and validation. Sci Total Environ 458-460:546-554

Barra R, Popp P, Quiroz R, Bauer C, Cid H, Von Tumpling W (2005) Persistent toxic substances in soils and waters along an altitudinal gradient in the Laja River Basin, Central Southern Chile. Chemosphere 58:905-915

Bettinetti R, Quadroni S, Manca M, Piscia R, Volta P, Guzzella L, Roscioli C, Galassi S (2012) Seasonal fluctuations of DDTs and PCBs in zooplankton and fish of Lake Maggiore (Northern Italy). Chemosphere 88:344-351

Breivik K, Sweetman A, Pacyna JM, Jones KC (2002) Towards a global historical emission inventory for selected PCB congeners - a mass balance approach. 1. Global production and consumption. Sci Total Environ 290:181-198

Dalla Valle M, Jurado E, Dachs J, Sweetman AJ, Jones KC (2005) The maximum reservoir capacity of soils for persistent organic pollutants: implication for global cycling. Environ Pollut 134:153-164

Davidson DA, Wilkinson AC, Blais JM, Kimpe LE, McDonald KM, Schindler DW (2003) Orographic cold-trapping of persistent organic pollutants by vegetation in mountains of Western Canada. Environ Sci Technol 37:209-215

de Voogt P, Brinkman UAT (1989) Production, properties and usage of polychlorinated biphenyls. In: Halogenated biphenyls, terphenyls, naphthalenes, dibenzodioxins and related products. Elsevier, Amsterdam

DLgs 152/06. Decreto legislativo: Norme in materia Ambientale. Published in "Gazzetta Ufficiale n. 88 del 14 aprile 2006Supplemento Ordinario n. 96"

Esposito V, Maffei A, Brino D, Varvaglione B, Ficocelli S, Capoccia C, Spartera M, Giua R, Blonda M, Assennato G (2014) POP emissions from a large sinter plant in Taranto (Italy) over a five-year period following enforcement of new legislation. Sci Total Environ 491492:118-122

ETAD-The Ecological and Toxicological Association of Dyes and Organic Pigments Manufacturers. ETAD Position on the presence of traces of PCBs in some organic pigments. 2011:http:/www.etad. $\mathrm{com} /$ documents/Downloads/publications/etad + position + on + the + presence + of + pcbs + in + pigments.pdf

Frame GM, Wagner RE, Carnahan JC, Brown JC, May RJ, Smullen LA, Bedard DL (1996) Comprehensive, quantitative, congener-specific analyses of eight aroclors and complete $\mathrm{PCB}$ congener assignments on DB-1 capillary GC columns. Chemosphere 33:603-623

Fu J, Wang T, Eang P, Qu G, Wang Y, Zgand Q, Zhang A, Jiang G (2012) Temporal trends (2005-2009) of PCDD/Fs, PCBs, PBDEs in rice hulls from an e-waste dismantling area after stricter environmental regulations. Chemosphere 88:330-335

Gouin T, Thomas GO, Chaemfa C, Harner T, Mackay D, Jones KC (2006) Concentrations of decabromodiphenyl ether in air from Southern Ontario: implications for particle-bound transport. Chemosphere 64:256-261
Grimalt JO, Fernandez P, Berdie L, Vilanova RM, Catalan J, Psenner R, Hofer R, Appleby PG, Rosseland BO, Lien L, Massabuau JC, Battarbee RW (2001) Selective trapping of organochlorine compounds in mountain lakes of temperate areas. Environ Sci Technol 35:2690-2697

Guazzoni N, Comolli R, Mariani L, Cola G, Parolini M, Binelli A, Tremolada P (2011) Meteorological and pedological influence on the PCBs distribution in mountain soils. Chemosphere 83:186-192

Harner T, Shoeib M, Diamond M, Stern G, Rosenberg B (2004) Using passive air samplers to assess urban-rural trends for persistent organic pollutants. 1. Polychlorinated biphenyls and organochlorine pesticides. Environ Sci Technol 38:4474-4483

Harner T, Shoeib M, Diamond M, Ikonomou M, Stern G (2006) Passive sampler derived air concentrations of PBDEs along an urban-rural transect: spatial and temporal trends. Chemosphere 64:262-267

Helyar SG, Patel B, Headington K, El Assal M, Chatterjee PK, Pacher P, Mabley JG (2009) PCB-induced endothelial cell dysfunction: role of poly(ADP-ribose) polymerase. Biochem Pharmacol 78:959-965

Hippelein M, McLachlan MS (1998) Soil/air partitioning of semivolatile organic compounds. 1. Method development and influence of physical-chemical properties. Environ Sci Technol 32:310-316

Hippelein M, McLachlan MS (2000) Soil/air partitioning of semivolatile organic compounds. 2. Influence of temperature and relative humidity. Environ Sci Technol 34:3521-3526

$\mathrm{Hu}$ D, Hornbuckle KC (2010) Inadvertent polychlorinated biphenyls in commercial paint pigments. Environ Sci Technol 44:2822-2827

Jaward FM, Farrar NJ, Harner T, Sweetman AJ, Jones KC (2004) Passive air sampling of PCBs, PBDEs, and organochlorine pesticides across Europe. Environ Sci Technol 38:34-41

Johnson KE, Knopperb LD, Schneider DC, Ollson CA, Redimer KJ (2009) Effects of local point source polychlorinated biphenyl (PCB) contamination on bone mineral density in deer mice (Peromyscus maniculatus). Sci Total Environ 407:5050-5055

Lei YD, Wania F (2004) Is rain or snow a more efficient scavenger of organic chemicals? Atmos Environ 38:3557-3571

Li Y-F, Harner T, Liu L, Zhang Z, Ren N-Q, Jia H, Ma J, Sverko E (2010) Polychlorinated biphenyls in global air and surface soil: distributions, air-soil exchange, and fractionation effect. Environ Sci Technol 44:2784-2790

Meijer SN, Steinnes E, Ockenden WA, Jones KC (2002) Influence of environmental variables on the spatial distribution of PCBs in Norwegian and U.K. soils: implications for global cycling. Environ Sci Technol 36:2146-2153

Meijer SN, Ockenden WA, Sweetman AJ, Breivik K, Grimalt JO, Jones KC (2003) Global distribution and budget of PCBs and HCB in background surface soils: implications for sources and environmental processes. Environ Sci Technol 37:667-672

Meyer T, Wania F (2008) Organic contaminants amplification during snowmelt. Water Res 42:1847-1865

Meyer T, Lei YD, Wania F (2006) Measuring the release of organic contaminants from melting snow under controlled conditions. Environ Sci Technol 40:3320-3326

Moeckel C, Nizzetto L, Di Guardo A, Steiness E, Freppaz M, Filippa G, Camporini P, Benner J, Jones KC (2008) Persistent organic pollutants in boreal and montane soil profiles: distribution, evidence of process and implication for global cycling. Environ Sci Technol 42: 8374-8380

Motelay-Massei A, Harner T, Shoeib M, Diamond M, Stern G, Rosenberg B (2005) Using passive air samplers to assess urbanrural trends for persistent organic pollutants and polycyclic aromatic hydrocarbons. 2. Seasonal trends for PAHs, PCBs, and organochlorine pesticides. Environ Sci Technol 39:5763-5773

Nizzetto L, Jarvis A, Brivio PA, Jones KC, Di Guardo A (2008) Seasonality of the air-forest canopy exchange of persistent organic pollutants. Environ Sci Technol 42:8778-8783 
Pan B, Xing BS, Liu WX, Tao S, Lin XM, Zhang XM et al (2006) Distribution of sorbed phenanthrene and pyrene in different humic fractions of soils and importance of humin. Environ Pollut 143:24 33

Pozo K, Harner T, Shoeib M, Urrutia R, Barra R, Parra O, Focardi S (2004) Passive-sampler derived air concentrations of persistent organic pollutants on a North-South transect in Chile. Environ Sci Technol 38:6529-6537

SISS-Società Italiana delle Scienze del Suolo (2007) Escursione scientifica del convegno nazionale: la scienza del suolo nei territori montani e collinari. Milano-Chiavenna, 9-13 July 2007

Shoeib M, Harner T (2002) Characterization and comparison of three passive air samplers for persistent organic pollutants. Environ Sci Technol 36:4142-4151

Sweetman AJ, Dalla Valle M, Prevedouros K, Jones KC (2005) The role of soil organic carbon in the global cycling of persistent organic pollutants (POPs): interpreting and modelling field data. Chemosphere 60:959-972

Tremolada P, Villa S, Bazzarin P, Bizzotto E, Comolli R, Vighi M (2007) POPs in mountain soils from the Alps and Andes: suggestions for a 'precipitation effect' on altitudinal gradients. Water Air Soil Pollut 188:93-109

Tremolada P, Parolini M, Binelli A, Ballabio C, Comolli R, Provini A (2009a) Preferential retention of POPs on the northern aspect of mountains. Environ Pollut 157:3298-3307

Tremolada P, Parolini M, Binelli A, Ballabio C, Comolli R, Provini A (2009b) Seasonal changes and temperature-dependent accumulation of polycyclic aromatic hydrocarbons in high-altitude soils. Sci Total Environ 407:4269-4277

Tremolada P, Comolli R, Parolini M, Moia F, Binelli A (2010) One-year cycle of DDT concentrations in high-altitude soils. Water Air Soil Pollut 217:407-419

Tremolada P, Guazzoni N, Smillovich L, Moia F, Comolli R (2012) The effect of the organic matter composition on POP accumulation in soil. Water Air Soil Pollut 223:4539-4556

Tremolada P, Guazzoni N, Parolini M, Rossaro B, Bignazzi MM, Binelli A (2014) Predicting PCB concentrations in cow milk: validation of a fugacity model in high-mountain pasture conditions. Sci Total Environ 487:471-480

Turrio-Baldassarri L, Abate V, Alivernini S, Battistelli CL, Carasi S, Casella M, Iacovella N, Iamiceli AL, Indelicato A, Scarcella C, La Rocca C (2007) A study on PCB, PCDD/PCDF industrial contamination in an mixed urban/agricultural area significantly affecting the food chain and the human exposure. Part I: soil and feed. Chemosphere 67:1822-1830

Van Caneghem J, Block C, Vandecasteele C (2014) Destruction and formation of dioxin-like PCBs in dedicated full scale waste incinerators. Chemosphere 94:42-47

Van Drooge BL, Grimalt JO, Camarero L, Catalan J, Stuchlik E, Garcia CJT (2004) Atmospheric semivolatile organochlorine compounds in European high-mountain areas (Central Pyrenees and High Tatras). Environ Sci Technol 38:3525-3532

Vighi M (2006) SETAC Europe Workshop Milan, Italy, 1-3 July 2004 Department of Environmental Sciences, University of MilanoBicocca 'The role of high mountains in the global transport of persistent organic chemicals'. Ecotoxicol Environ Saf 63:108-112

Wang X-P, Yao T-D, Cong Z-Y, Yan X-L, Kang S-C, Zhang Y (2006) Gradient distribution of persistent organic contaminants along northern slope of central-Himalayas, China. Sci Total Environ 372:193202

Wang X-P, Yao T-D, Cong Z-Y, Yan X-L, Kang S-C, Zhang Y (2007) Distribution of persistent organic pollutants in soil and grasses around Mt. Qomolangma, China. Arch Environ Contam Toxicol 52:153-162

Wania F, Hoff JT, Jia CQ, Mackay D (1998a) The effects of snow and ice on the environmental behavior of hydrophobic organic chemicals. Environ Pollut 102:25-41

Wania F, Haugen JE, Lei YD, Mackay D (1998b) Temperature dependence of atmospheric concentrations of semivolatile organic compounds. Environ Sci Technol 32:1013-1021

WMO-World Meteorological Organisation (1996) Guide to meteorological instruments and methods of observation (WMO guide n. 8), Sixth edition, loose-leaf; updated by supplements when necessary, Geneva, $\mathrm{CH}$ 